\title{
A botanical nano ozonated composition with maximum bioavailability for burns
}

\begin{abstract}
The present patent-pending invention relates to a topical pharmaceutical nano composition (with maximum bioavailability) for burn was developed. Random clinical study on 100 volunteers showed very fast and effective relief of burns on all patients of both sexes. For severe burns cases it was observed burns disappeared in less than a week. Observed results showed excellent results for all ages with no adverse or side effects.
\end{abstract}

Volume 3 Issue 6 - 2017

\author{
Awad Mansour,' Ammar Mansour² \\ 'University of Akron, USA \\ ${ }^{2}$ Essraa Hospital, Jordan
}

Correspondence: Awad Mansour, University of Akron, $\mathrm{OH}$, USA, Tel 96227278 278, Email profmansour@gmail.com

Received: August 10, 2017| Published: August 31, 2017

\section{Description of the invention}

\section{Burns}

Burns can be minor medical problems or life-threatening emergencies. Many people die each year from fire-related burn injuries. Electricity and chemicals also cause severe burns. Scalding liquids are the most common cause of burns in children. Treatment of burns depends on the location and severity of the injury. Sunburns and small scalds can usually be treated at home. Deep or widespread burns need immediate medical attention. People with severe burns often require treatment at specialized burn centres. They may need skin grafts to cover large wounds or to minimize scarring with deep wounds. And they may need emotional support and months of followup care, such as physical therapy. Unfortunately, number of burn cases has recently increased by tens of millions because of wars in many countries worldwide and $99 \%$ of patients could not find fast and helpful treatment! Though there are number of creams and ointments available in the international market but they are not effective!!

\section{Causes}

\section{Many things can cause burns, including}
a. Fire
b. Hot liquid or steam
c. Hot metal, glass or other objects
d. Electrical currents
e. Radiation from X-rays or radiation therapy to treat cancer
f. Sunlight or ultraviolet light from a sunlamp or tanning bed
g. Chemicals such as strong acids, lye, paint thinner or gasoline
h. Abuse
i. Wars and chemical weapons.

\section{Complications}

Deep or widespread burns can lead to many complications, including:

\section{Infection}

Burns can leave skin vulnerable to bacterial infection and increase your risk of sepsis. Sepsis is a life-threatening infection that travels through the bloodstream and affects your whole body. It progresses rapidly and can cause shock and organ failure.

\section{Low blood volume}

Burns can damage blood vessels and cause fluid loss. This may result in low blood volume (hypovolemia). Severe blood and fluid loss prevents the heart from pumping enough blood to the body.

\section{Dangerously low body temperature}

The skin helps control the body's temperature, so when a large portion of the skin is injured, you lose body heat. This increases your risk of a dangerously low body temperature (hypothermia). Hypothermia is a condition in which the body loses heat faster than it can produce heat.

\section{Breathing problems}

Breathing hot air or smoke can burn airways and cause breathing (respiratory) difficulties. Smoke inhalation damages the lungs and can cause respiratory failure.

\section{Scarring}

Burns can cause scars and ridged areas caused by an overgrowth of scar tissue (keloids).

\section{Bone and joint problems}

Deep burns can limit movement of the bones and joints. Scar tissue can form and cause shortening and tightening of skin, muscles or tendons (contractures). This condition may permanently pull joints out of position.

\section{Compositions}

Prof. Awad Mansour, has arrived at an ozonated nano natural cream with maximum bioavailability to solve this problem in less than a week!!! Dr. Ammar Mansour (MD) at AL-Essra Hospital and Dr. B Khasawneh (MD) at Yarmouk University Clinic tried this cosmetic product on more than 100 volunteers with excellent results!!! 
Compositions comprising botanical ozonated oils, active agents, etc., can be produced and used in accordance with the present invention that is useful to treat or affect burns. For example, the present invention relates to compositions, preferably for topical or local use, which comprise one or more of the following ingredients, including, but not limited to, bee propolis, oregano oil, aloe-vera gel, olive oil, witch hazel and German chamomile oil The compositions can produce one or more of the following pharmacological effects, including, but not limited to, antibacterial, antiviral, etc. Ozonated oil is made with high quality, organic, extra-virgin, cold pressed oil that is put through a process of "ozone injection", which is bubbling ozone into the liquid for an extended period of time. Many companies use a cheap corona discharge ozone generator that can lead to contamination. For purity and quality a cold plasma ozone generator should always be used.

\section{The top benefits of ozonated essential oils}

Ozonated Oil holds a variety of health benefits, but is most commonly used for conditions of the skin and external body, much as you would use a therapeutic salve or cream. As a massage paste, the ozonide acts as an antioxidant, allowing lactic acid and toxins to be released from the pores of the skin. Other benefits and uses include:

a. Stimulation of growth for skin cells

b. Speeds up healing-time for skin wounds and ulcers

c. Cleans and sterilizes the epidermis

d. Reduces swelling and redness

e. Calms the nerves and reduces the amount of pain in skin conditions

f. May increase cellular function and cellular memory

g. Acts as a free radical scavenger on harmful toxins

h. Acts as a moisturizing facial conditioner (leave on for $20 \mathrm{minu}-$ tes and promptly remove)

i. Aids in healing processes and reduces scarring

j. Promotes healthy skin conditions

k. Good for removing makeup

1. Good for animal wounds, as it is all natural, and can be licked

m. Sunburn of the skin

n. Insect bites and stings

o. Infections of the sebaceous glands (sweat)

p. Can be used as a natural under arm deodorant

q. Burns - One of the best natural remedies

r. Sore muscles (rub as a massage paste)

s. Cellulite Reduction

t. Wrinkles

u. Ringworm

v. Bed Sores

w. Cuts \& Burns
x. Skin Yeast
y. Carbuncles
z. Diaper Rash
aa. Tinea Versicolor

ab. Dermatitis

Bee propolis: It has been found to be more effective than some pharmaceutical applications against vaginal herpes, burns, varicose veins, eczema, psoriasis and all skin disorders as well as peptic ulcer. Tests also suggest that propolis may significantly reduce the chance of an advanced burns wounds.

Ozonated chamomile oil: ${ }^{2}$ It is a natural remedy that aids in soothing irritated skin and reducing pain. You can use ointment and creams that contains Chamomile oil or apply it directly to the affected area.

Ozonated olive oil: ${ }^{2}$ It is another essential oil with anti-inflammatory and antioxidant properties. It increases the elasticity of blood vessels and is useful in reducing inflammation.

Ozonated wild oil of oregano: ${ }^{3}$ It is an edible medicinal grade essential oil that is grown from a wild species of oregano especially in the Mediterranean. There are a multitude of conditions that Oil of Oregano treats, but the most famous use is its ability to kill infections in the body. Most organisms cannot survive when exposed to the powerful phenols (carvacrol and thymol) which are the active ingredient in this Wild Oil of Oregano. These ingredients work well on their own but have an added potency when found together in nature. The ancient Greeks were among the first to take advantage of oregano's medicinal qualities and termed the spice oregano meaning delight of the mountains. Here is a list of the powerful actions of Oil of Oregano

a. Potent antioxidant

b. Anti-venom (spiders, scorpions, bees, ants and snakes)

c. Anti-viral

d. Anti-fungal

e. Anti-parasitic

f. Natural Anesthetic (pain reducer)

g. Mucolytic (thins mucous)

h. Anti-tussive (decreases cough)

i. Antispasmodic

The anti inflammatory properties of oregano oil inhibit causes of bacteria. ${ }^{4}$ Another amazing bacterial treatment is employing a mixture of 3 drops of ozonated oregano oil and 1 tablespoon of ozonated olive oil onto the affected area.

Witch hazel: ${ }^{5}$ It is used to stop bleeding and is believed to be effective on both internal and external injuries. It is used to stop the bleeding on cuts, reduce bruising directly after an injury and as part of the treatment for stomach ulcers. It is believed that the tannins present in witch hazel (especially the bark), along with various oils, help speed coagulation.

Calendula (Calendula officinalis): ${ }^{6}$ Commonly known as marigold, calendula has a long history of use as a treatment for burns and other skin inflammations. Calendula is antiseptic and anti-inflammatory, 
helping to promote healing by stimulating the production of the outer skin cells. Calendula may be used for acute dermatitis from radiation therapy, mild skin burns, scalds, razor burns, mild sunburn and even windburn. It acts immediately and effectively in the prevention of blisters and scar tissue. It may also be used in the case of chemical burn as an eye wash. Calendula is most effective when it is used as a compress applied to the burn area. Note that calendula is a member of the composite family along with ragweed, and may cause allergic reactions

Lavender pure essential oil: ${ }^{7}$ It is considered by many aroma therapists as one of the premier remedies for burns. It is antiseptic and analgesic and is the only essential oil that can be applied directly to the skin without dilution. It prevents infection, reduces inflammation, promotes healing and reduces or prevents scar tissue formation. It is considered the safest essential oil to use with children, as evidenced by the many lavender-scented baby products on the market. The scent of lavender also has calming effects, which soothe the nerves after injury.

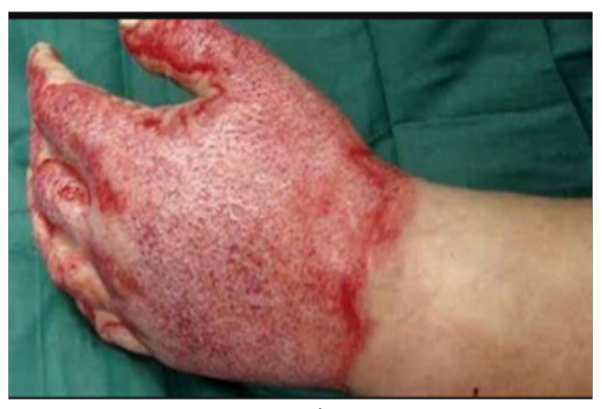

A

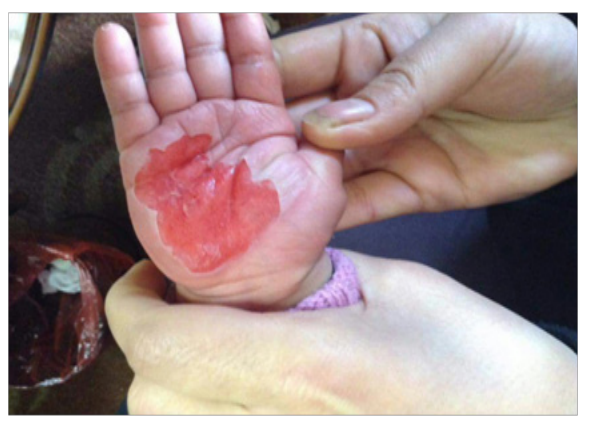

D

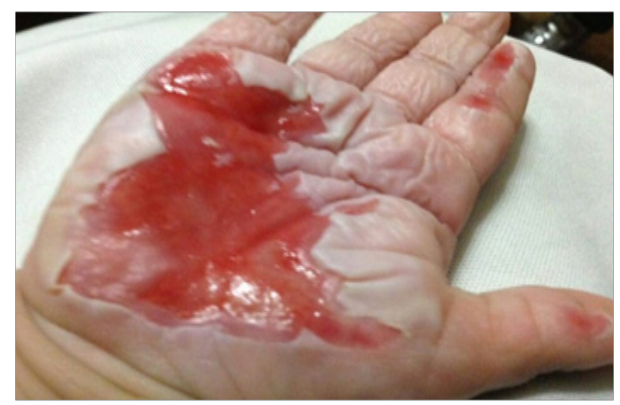

B

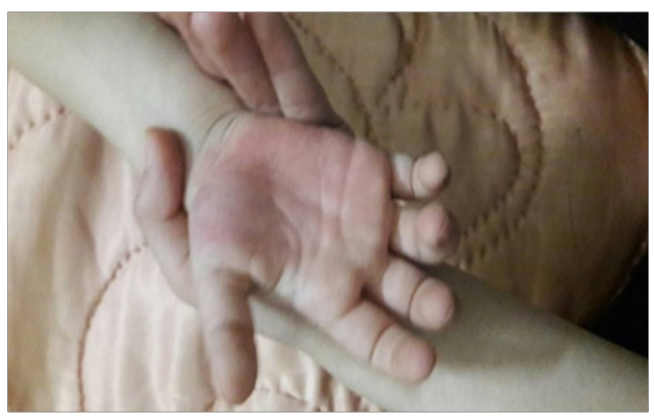

E

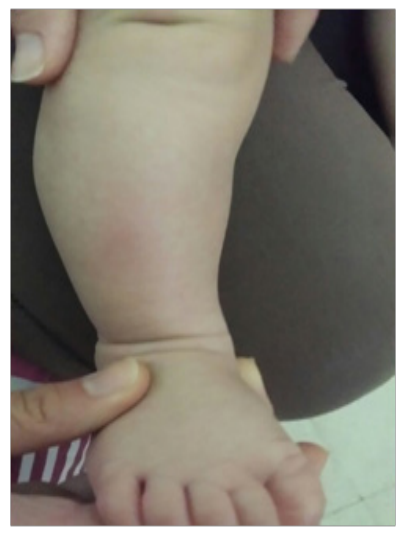

Aloe-vera: ${ }^{8}$ It is one of nature's best ingredients for treating burns. The anti-inflammatory and therapeutic properties of aloe vera help reduce the irritation of burns.

\section{Maximum bioavailability}

The herbal composition if used as an oral formulation its bioavailability will be poor compared to a topical (external) to give good bioavailability. It was found that this cream with its nano particle size did give maximum bioavailability effect.

\section{Summary of the invention}

The present invention relates to a topical pharmaceutical composition for treatment of burns (Figure $1 \& 2$ ). The composition for treating disorder, preferably formed of nano gel or nano cream, contains be propolis, witch hazel, ozonated oregano oil, lavender oil, aloe-vera gel, ozonated olive oil, calendula oil , and ozonated German chamomile oil. 


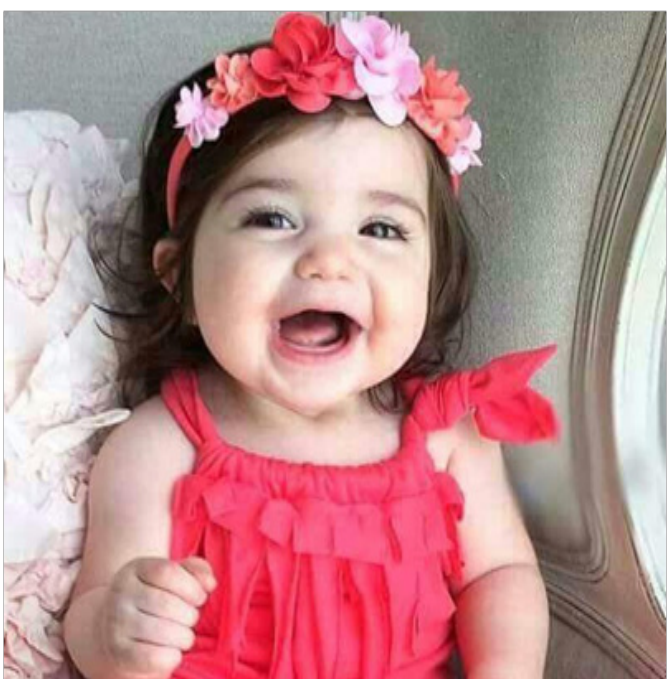

Figure 2 Child after treatment.

\section{Examples of pre-clinical results}

The following results were obtained at the clinic of University of Dr. B Khasawneh at Yarmouk University Clinic in Jordan. One hundred patients with symptomatic, prolapsed irreducible burns were treated with nano ozonated cream for one week. Some patients with second degree healing results were faster; it took them 3 days only to rid of burns symptoms while patients with third and forth degree with bleeding it to them 7 days for pain relief and disappearance of bleeding (Table 1).

Table I Effect of nano cream on burns symptoms

\begin{tabular}{|c|c|c|c|c|c|}
\hline \multirow[t]{2}{*}{ Grade } & \multirow{2}{*}{$\begin{array}{l}\text { No. of } \\
\text { patients }\end{array}$} & \multirow[t]{2}{*}{ Symptoms } & \multirow{2}{*}{$\begin{array}{l}\text { Treatment } \\
\text { time }\end{array}$} & \multicolumn{2}{|c|}{ Case status } \\
\hline & & & & Before & After \\
\hline I & 22 & Itching & 2 Days & Mild & Cured \\
\hline 3 & 10 & Bleeding & 7 Days & Severe & Cured \\
\hline I & 28 & $\begin{array}{l}\text { Pain, } \\
\text { Discomfort }\end{array}$ & 4 Days & Mild & Cured \\
\hline 2 & 10 & $\begin{array}{l}\text { Scars } \\
\text { Around } \\
\text { Burns }\end{array}$ & 3 Days & Severe & Cured \\
\hline I & 12 & $\begin{array}{l}\text { Itching \& } \\
\text { Pain }\end{array}$ & 2 Days & Mild & Cured \\
\hline 3 & 5 & $\begin{array}{l}\text { Bleeding \& } \\
\text { Joint Pain }\end{array}$ & 7 Days & Severe & Cured \\
\hline 3 & 7 & $\begin{array}{l}\text { Itching \& } \\
\text { Severe Pain }\end{array}$ & 3 Days & Severe & Cured \\
\hline 3 & 3 & $\begin{array}{l}\text { Bleeding \& } \\
\text { Itching }\end{array}$ & 8 Days & Severe & Cured \\
\hline 4 & 3 & $\begin{array}{l}\text { All } \\
\text { Symptoms }\end{array}$ & I4 Days & Severe & Cured \\
\hline
\end{tabular}

\section{Safety and toxicity study}

Toxicity study performed on mice in the animal house showed that the composition is free of adverse effects especially on liver, kidneys, lipid and other body organs.

\section{Conclusion}

This patented botanical nano cream is expected to help tens of millions of burns patients of both sexes worldwide. Double blind is still needed to give more reliable results.

\section{Acknowledgements}

Effots of Dr Bassam Khasawneh during the clinical period of this work is highly appreciated.

\section{Conflict of interest}

The author declares no conflict of interest.

\section{References}

1. Olczyk P, Koprowski R, Kaźmierczak J, et al. Bee Pollen as a Promising Agent in the Burn Wounds Treatment. Evid Based Complement Alternat Med. 2016;2016:8473937.

2. Best 12 Essential oils and recipes for burns. Essential oil Benefits. 2016.

3. Burns: How to treat with natural remedies. USA: Annies Remedy Essential Oils \& Herbs; 2016.

4. Sienkiewicz M, Wasiela M, Głowacka A. The antibacterial activity of oregano essential oil (Origanum heracleoticum L.) against clinical strains of Escherichia coli and Pseudomonas aeruginosa. Med Dosw Mikrobiol. 2012;64(4):297-307.

5. Natural Burn Treatment. USA: Survival Medicine; 2011.

6. Matthew J Leach. Calendula officinalis and wound healing: a systematic review. Wounds. 2008;20(8):236-243.

7. Meagan. Lavender: your secret weapon for burns. England, UK; 2013.

8. Zora Degrandpre. Wiki How to use aloe vera to treat burns. USA: Expert Reviewed; 2016.

9. Mike Adams. Review of global healing center: ozonated skin salve, oxy-powder, slimirex and other revolutionary health products. USA: Natural News; 2008. 